\title{
CRYPTO CURRENCY APPLICATIONS IN FINANCIAL MARKETS: FACTORS AFFECTING CRYPTO CURRENCY PRICES
}

\author{
DOI: 10.17261/Pressacademia.2020.1235 \\ PAP- V.11-2020(7)-p.34-37
}

\section{E. Asena Deniz'1, Dilek Teker ${ }^{2}$}

${ }^{1}$ Maya Plastic, Istanbul, Turkey

asendnz@gmail.com, ORCID: 0000-0003-1772-9714

${ }^{2}$ Isik University, Faculty of Economics and Administrative Sciences, Department of Management, Istanbul, Turkey. dilek.teker@isikun.edu.tr, ORCID: 0000-0002-3893-4015

\section{To cite this document}

Deniz, E.A., Teker D. (2020). Crypto currency applicatıons in financıal markets: factors affectıng crypto currency prices. PressAcademia Procedia (PAP), V.11, p.34-37

Permanent link to this document: http://doi.org/10.17261/Pressacademia.2020.1235

Copyright: Published by PressAcademia and limited licensed re-use rights only.

\section{ABSTRACT}

Purpose- As the cryptocurrency market is beginning to attract investors, a new portfolio of cryptocurrencies has been published in the literature on macro-economic factors affecting these currencies. This research also aimed to identify the interaction between gold, brent oil, Bitcoin, Ethereum and Ripple.

Methodology- The database includes the Daily prices of Bitcoin, Ethereum, Ripple, gold and brent oil prices between the period of 03.04.2018-31.12.2020 which consist of 500 daily data. Natural logaritm for each indicator is used. First, the stationarity of the series were analyzed with ADF (Augmented Dickey Fuller) unit root test. Lag lengths are determined. Interactions between the series were analyzed by the Johansen Cointegration test, Granger Causality test, Impulse- Response Function and Variance Decomposition method.

Findings- The series are found out to be stationary at first difference. According to the cointegration test result, cointegration could not be found between our data. According to Granger causality analysis, only one-way relationship was found from bitcoin to gold. Impulse response graphs indicate that all variables respond in a reducing way to reducing shocks occurred in each indicator. Shocks have lost their effect on average in 2 days.

Conclusion- The results indicate that the effect of gold and brent oil prices on bitcoin, ethereum, ripple daily prices do not have a strong effect. The results may be beneficial for investors to consider diversification for the portfolios.

Keywords: Crytocurrency, Johansen Co-integration Test, Granger Casuality Test, Impulse- Response Function and Variance Decomposition JEL Codes : G10, G11, G15

\section{INTRODUCTION}

Depending on the development of technology, the prevalence of internet use and today's conditions play a major role in the spread of ecommerce. With this development, cryptocurrencies are also beginning to spread. oday, cryptocurrencies, which have started to make their name known with bitcoin, are beginning to take an important place in the world of finance. It is defined as virtual coins that take advantage of cryptographic systems, which are not tied to a central authority, and whose security level is greater than that of other coins. There are currently 2981 cryptocurrencies. However, the very well knowns are Bitcoin (BTC), ), Ethereum (ETH), Ripple (XRP), Tether (USDT) Bitcoin Cash (BCH), Bitcoin SV (BSV) Litecoin (LTC). Since cryptocurrencies are a product of the virtual economy, transactions can be made easily and quickly over the Internet without the need for banking transactions. Although cryptocurrencies have the characteristics of being a means of investment and savings just like traditional currencies, they are not subject to a central authority and are not subject to legal regulations, which distinguishes virtual currencies from traditional currencies. With the increase in interest in these currencies, investors have star ted to create a new portfolio for themselves. In this study, the relationship between the gold and brent oil of the Bitcoin, Ethereum, Ripple with high trading volume and high market value in the crypto money market is analyzed using the VAR model. Johansen cointegration tests and Granger causality tests are conducted to evaluate the relationships between the criteria. As a result of the study, it is predicted that crypto money can only be used as an investment alternative.

\section{LITERATURE REVIEW}

In an article published by Nakamoto in 2008 , blockchain and bitcoin concepts were announced. The Nakamoto distributed database with bitcoin, which was introduced with the idea of cryptocurrency, suggested the idea that it could be the solution to the proble m of multiple spending on virtual currency. In 2011, Herpel defined digital money as transparent and easy to access data that can be used over the 
internet without an intermediary institution. Sonmez (2014) explored the development, properties and functioning of Bitcoin, as well as its place in the world and its development and economy in Turkey and he determined the strengths and weaknesses of Bitcoin and made a current situation analysis regarding the virtual currency. Baek and Elbeck (2014) used daily return data of variables affecting Bitcoin returns to study bitcoin and S\&P 500 index volatility. As a result of the research, it has been determined that Bitcoin has more volatility than S\&P 500 Index. The research also indicated that the bitcoin market is highly speculative. Alexander, Gasser and Weinmayer (2015) claimed that Bitcoin could contribute to the return of the portfolio by reducing the portfolio risk. Szetela v.d (2016) attempted to measure the relationship between Bitcoin and the U.S. Dollar, Euro and Chinese yuan using Arma and GARCH analysis. Among the findings, there was no re lationship between the ARMA model and the relationship between Bitcoin and the US Dollar, Euro and Chinese yuan in the GARCH model. Estrada (2017) applied a Granger causality test to price movements of Bitcoin and the S\&P500 index between 15.09.2010-13.04.2017 and sought to establish the causality between them. However, there is no mutual causality between the two variables. Zhu et al. (2017) analyzed the economic factors that may affect Bitcoin prices using the vector error correction model. As a result of the analysis, while the Consumer Price Index, Dow Jones Index averages and the US Dollar Index had a negative and long-term effect on Bitcoin prices, it was found that gold prices did not have any effect on Bitcoin prices in the long term. Chuen, Guo and Wang (2018) examined the static correlation between cryptocurrencies and traditional investments, concluding that cryptocurrency is a good option in terms of diversification of portfolio risk. Güleç (2018), in their study, they analyzed the relationship between bitcoin and financial indicators with Johansen Cointegration and the Granger causality test. Kanat and Öget (2018), working with Bitcoin prices in the short and long-term relations between Turkey and the G7 countries' stock markets (causality) were examined. Yıldırım (2018) analyzed the relationship between daily bitcoin and gold prices with the Johansen Cointegration Test.

\section{DATA AND METHODOLOGY}

The study was carries out with daily data of Bitcoin, Ethereum,Ripple, gold and brent oil prices between the periods April 03 , 2018 to December 31, 2020 that consist 500 data. Natural logarithms of all series were used in the analysis. The data is obtained from https://coinmarketcap.com. In this study, the stationary of the series were analyzed with ADF (Augmented Dickey Fuller) unit root tests. Interactions between the series were analyzed by the Johansen Co-integration Test, Granger Casuality Test, Impulse-Response Function and Variance Decomposition methods based on the VAR (Vector Aotoregressive) method. Unit root testing is an important methodology for testing whether shocks to a particular time series have a permanent effect or a transitory effect. The presence of a unit root suggests that after a shock the series has no tendency to revert to its equilibrium value or stable path. On the other hand, if it is possible to reject the null hypothesis of unit root then this indicates that the shocks to a series only have a transitory effect. The hypotheses for unit root tests areas:

$H_{0}$ : Series are not stationary.

$H_{1}$ : Series are stationary.

Stationarity of series can be determined by unit root tests. The stability of the series is tested by looking at whether the time series contains unit roots (Çabuk ve Balcılar, 1998). In the DF test, all time series are expressed in first-order autoregressive processes; however, it is possible to use DF tests to test higher order autoregressive processes. (Enders,1995). In 1981, Dickey and Fuller developed this test and reorganized it as an ADF test. In the study, the stationary level of the series was tested with ADF Test. Table 1 indicates the outputs of ADF unit root tests.

Table 1: Unit Root Test Results

\begin{tabular}{|l|l|c|c|c|c|c|}
\hline Değişken & Sembol & ADF Test İstatistiği & \multicolumn{2}{|l|}{ Mac-Kinnon Kritik Değerleri } & Olasılık* \\
\hline & & & $\mathbf{1} \%$ & $\mathbf{5} \%$ & $\mathbf{1 0 \%}$ & \\
\hline Altın & & $-28,9458$ & $-3,443254$ & $-2,867124$ & $-2,569806$ & 0,0000 \\
\hline BrentPetrol & & $-24,73157$ & $-3,443254$ & $-2,867124$ & $-2,569806$ & 0,0000 \\
\hline Bitcoin & BTC & $-22,93680$ & $-3,443254$ & $-2,867124$ & $-2,569806$ & 0,0000 \\
\hline Ethereum & ETH & $-23,22374$ & $-3,443254$ & $-2,867124$ & $-2,569806$ & 0,0000 \\
\hline Ripple & XRP & $-21,46952$ & $-3,443254$ & $-2,867124$ & $-2,569806$ & 0,0000 \\
\hline
\end{tabular}

Vector autoregressive (VAR) Model is a system of equations that allows the reciprocal interaction of fundamental variables thought to be related to each other and shows how these variables move together. There are many criteria used in the literature to determine the delay length of an AR process. Criteria that have been evaluated in this study are as follows: Akaike's information criterion (AIC), Schwarz

information criterion (SIC), Hannan-Quinn criterion (HQC), Final prediction error (FPE). The methods specified according to the assumptions of the model created and the sample size can give different lag length criteria. The outputs for the lag length criteria figures out the length as 2 periods.

Johansen Cointegration Test is that when there are multiple explanatory variables, they are used to identify multiple cointeg ration relationships between these series. In fact, long-term relationships between variables can be revealed by cointegration analysis, where linear combinations of the time series, which are not actually stationary by themselves, constitute a stationary process at a certain integrated level. (Kocabıyık, 2016). It can be observed whether there is a long-term relationship with the Johansen Cointegration test. According to the test results, our probability value is greater than 0.05 . Therefore, according to our Hypothesis, H0 cannot be rejected, so there is no cointegration between these values. Table 2 indicates the outputs of Johansen Co-integration Results. 
Table 2: Johansen Cointegration Test Results

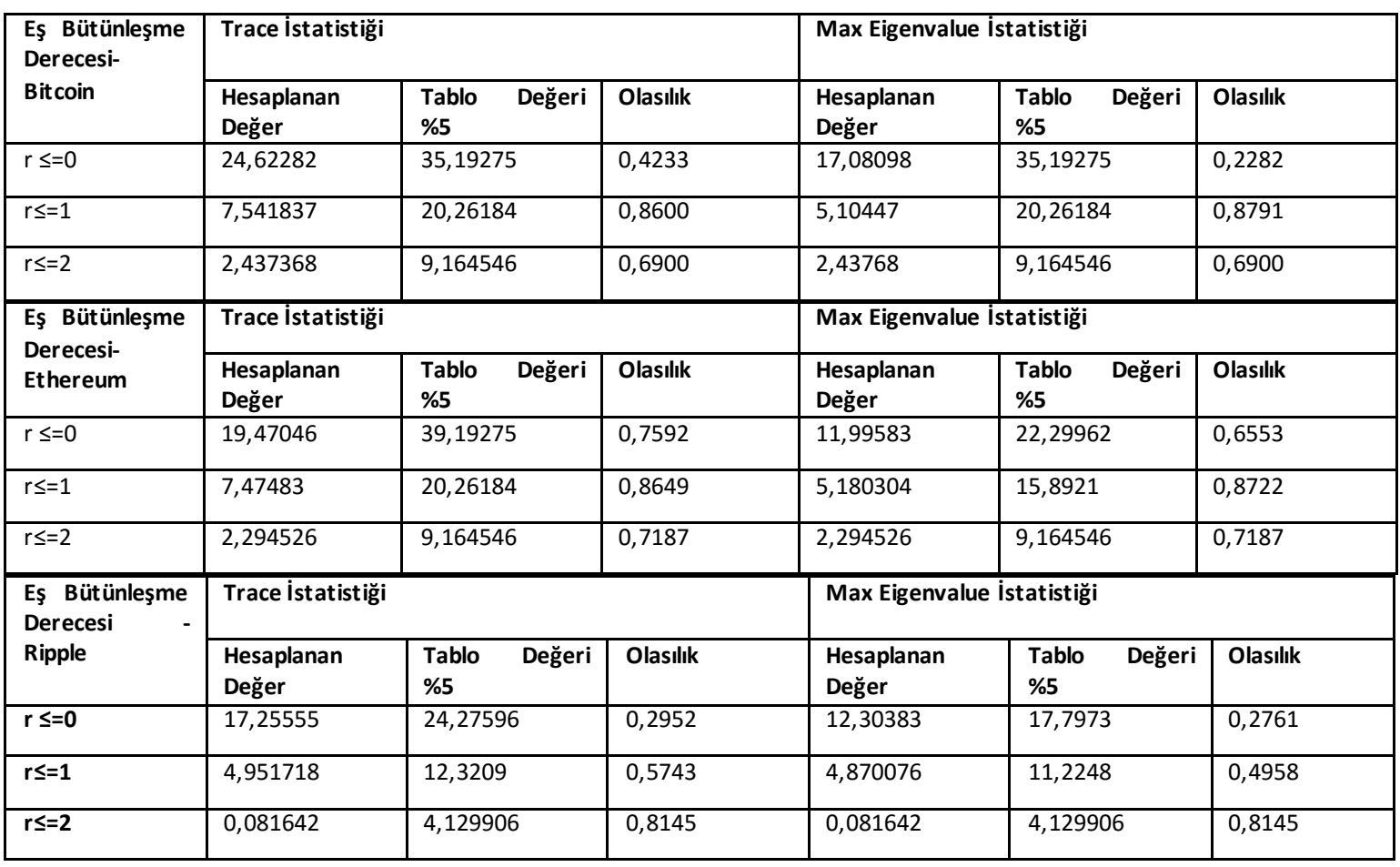

Granger Causality Analysis is performed to determine the direction of the relationship between variables. Statistically causality is the future estimated values of a time series variable, obtained by influencing the past period values of itself or another related time series variable. (Işığıçok, 1994). According to the results of the Granger causality test findings, the probability values are less than $5 \%$. Bitcoin is the Granger cause of gold. Brent Oil is Gold's Granger cause. Ethereum has no causal relationship with neither Gold nor Brent oil. Brent Oil is Gold's Granger cause. Ripple has no causal relationship with both Gold and Brent oil.

The impact-response functions reflect the impact of a standard error shock in one of the random error terms on the present and future values of the internal variables. Variance decomposition which is the most effective variable on a macroeconomic size; Whether this effective variable can be used as a policy tool is determined by the effect-response functions. (Özgen ve Güloğlu, 2004). It was observed that the shocks given to Bitcoin, Ethereum and Ripple have no significant effect on gold and Brent Oil. The same is validated for Gold and Brent oil. The given shocks lost their effect in an average of 2 days. Variance Decomposition is that distinguishes the change in one of the intrinsic variables as separate shocks affecting all the intrinsic variables is called variance decomposition. Impulse-Response functions demonstrate to what extent a standard deviation shock in one of the random error terms of the VAR model findings affects the present and future values of the internal variables. When the variance decomposition results for Bitcoin, Ethereum and Ripple are analyzed, the result is not meaningful. While close to $100 \%$ of the shock from bitcoin was self-explanatory in the first period, 10 . During the period, $99 \%$ of the shock itself is explained by $0.5 \%$ of gold and Brent oil. While close to $100 \%$ of the shock from Ethereum was self-explanatory in the first period, 10 . During the period, $99.4 \%$ of the shock is self-explained, $0.4 \%$ is over gold and $0.06 \%$ is over Brent Oil. While $100 \%$ of a shock coming to Ripple is announced from the first period, $99.8 \%$ of the shock above Ripple is explained by gold, and $0.01 \%$ of it is from brent oil in the last period.

\section{CONCLUSION}

In this study, the interaction between the closing prices of Bitcoin, Ethereum, Ripple, Gold and Brent Oil were analyzed. The series were examined by ADF and PP unit root tests and all series were observed to be I (1). Since VAR analysis can be done using stationary series; The data set I (1) is modeled. After the lag lengths were determined as 2nd degree, the Johansen Cointegration test and Granger Causality Test were performed. Based on the findings from this study, it can be understood that there was no significant interaction between Bitcoin, Ethereum, Ripple, Gold and Brent Oil. Interactions between the series were analyzed also by the Impulse-Response Function. Shocks have lost their effect on average in 2 days. Next Variance Decomposition method is based on the VAR (Vector Aotoregressive) method. Based on the findings obtained from this study, it can be understood that there is no significant interactions between Bitcoin, Ethere um, Ripple, Gold and Brent Oil. The result may be beneficial for investors to consider diversification for their portfolios. Investors may think of cryptocurrencies as an alternative investment tool to their savings. Since there is no tangible investment, the fact that the risks are greater than those of other investment instruments is also inevitable. The results may change when applied with other cryptocurrencies and other macroeconomic values. 


\section{REFERENCES}

C. Baek-M.Elbeck “Bitcoin's as an Investment or Speculative Vehicle? A First Look”. Applied Economics Letters, 2014, $22(1)$, s.30-34.

Chuen, D.L.K., Guo, L., Wang, Y. (2018). Cryptocurrency: A New Investment Opportunity?. The Journal of Alternative Investments. 20 (3). 1640. http://jai.iijournals.com/content/20/3/16

Çabuk, Altan, M., Balcılar, 1998, "What Does A Unit Root Mean? The Statistical and Economic Interpretation Of Unit Root Processes With A Survey Of Unit Root Test", Journal of the Faculty of Economics and Administrative Sciences, Cukurova University, Special Issue on Econometrics, 8, 289-332.

Eisl,A. Gasser,S.Weinmayer K. (2015) Caveat Emptor: Does Bitcoin Improve Portfolio Diversification?,SSRN Electronic Journal- Accessed: 15.06. 2020

Enders, Walter (1995), Applied Econometric Time Series, Birinci Baskı, Wiley. (New York: lowa State University).

Güleç, Ö. F., Çevik, E. and Bahadır, N. (2018). Investigation of the Relationship Between Bitcoin and Financial Indicators. Kırklareli University Journal of Faculty of Economics and Administrative Sciences, 7 (2), 18-37.

Herpel, M., (2011). 2011 Observations on the Digital Currency Industry, DGCmaga- zine.

Işıkçok, Erkan (1994). Causality Analysis in Time Series. Bursa: Uludağ University - Versitesi Printing House.

Kanat, E. and Öget, E. (2018). Bitcoin exchanges between Turkey and G7 country with a long and Analysis of Short-Term Relationship. Journal of Finance, Economics and Social Research, 3 (3), 601-614.

Kocabıyık Turan (2016) Analysis of Decision Stages in Johansen Cointegration Test. Süleyman Demirel University Journal of Social Sciences Institute. Number: Ciep Special Issue

Nakamoto S. (2008). Peer To Peer Electronic Cash System, https://bitcoin.org/ bitcoin. Taken from pdf. Accessed: 03/05/2020

Özgen, F.B. and Güloğlu, B. (2004). VAR Technical Analysis of the Economic Impact of Domestic Debt in Turkey. METU Studies in Development, 31: 93-114.

Sönmez, A., (2014). "Sanal Para Bitcoin", The Turkish Online Journal of Design, Art and Communication -TODJAC, 4(3): 1 - 14.

Szetela, B., Mentel, G., \& Gedek, S. (2016). Dependency analysis between Bitcoin and selected global currencies. Dynamic econometric models (Vol (16)), 133-144.

Zhu Y., Dickinson D. ve Li Jianjun (2017). Analysis on the influence factors of Bitcoin's price based on VEC model Financial Innovation 3:3, 113. DOI: $10.1186 / \mathrm{s} 40854-017-0054-0$

Yıldırım, H. (2018). Testing the Relationship Between Daily Bitcoin and Gold Prices: The Johansen Cointegration Test Between $2012-2013$. Journal of Human and Social Sciences Researches, 7 (4), 2328-2343. 